1 of 1 DOCUMENT

Global Environmental Politics

May 2009

\title{
What Have Future Generations Done for Me Lately?: Climate Change Causes, Consequences, and Challenges in the New Millennium
}

\author{
BYLINE: Maxwell T. Boykoff \\ SECTION: BOOK REVIEW ESSAY; Pg. 123
}

LENGTH: 2400 words

Cowie, Jonathan. 2007. Climate Change: Biological and Human Aspects. Cambridge: Cambridge University Press.

Gautier, Catherine. 2008. Oil, Water, and Climate. Cambridge: Cambridge University Press.

Moser, Susanne C., and Lisa Dilling, eds. 2007. Creating a Climate for Change: Communicating Climate Change and Facilitating Social Change. Cambridge: Cambridge University Press.

It is a brave new world, where people across the planet increasingly grapple with the causes and consequences of climate change. Detrimental impacts and dire forecasts have now been well-catalogued. People deal with climate-related challenges in their material lives through their ability to meet livelihood needs, and in their social and discursive spaces in terms of how considerations for climate action are meaningful. Initiatives and plans that were formerly confined to the climate-controlled quarters of high-level policy briefing rooms and scientific conference halls are increasingly prevalent around the kitchen table, bar stool, front porch and corner shop. There is an explosion of books and news coverage on climate change, and climate issues increasingly permeate entertainment and leisure. As this engagement grows, social and cultural movements shift more rapidly than the physical climate, thereby reshaping the terrain of possibility for our collective future.

Within these critical challenges reside possibilities for, as well as indications of, different future paths. Amid the white noise of daily activities, these signals take shape in ecological, meteorological, cultural, social, scientific and political events. For two recent instances, we can look to politics. In October, UK Prime Minister Gordon Brown announced a new Department for Energy and Climate Change (DECC), ${ }^{1}$ thus acknowledging that activities need to be stepped up more coherently to meet European Union and Kyoto Protocol targets and timetables. Upon taking up the post, newly appointed DECC chief Ed Miliband promptly called for tougher commitments than those made before, saying that 80 percent reductions of greenhouse gas emissions (GHG) were needed across the UK by $2050 .{ }^{2}$ In November, the world witnessed the US presidential election victory of Barack Obama, as well as what many anticipate is a revival of international climate negotiations. In the days immediately following the US election, stock prices for clean technology and green energy soared. 3 Along with ongoing high oil prices, the possible implementation of Obama's promised 10 year energy security and climate change plan--including investments of US\$ 150 billion in clean technologies over 10 years ${ }^{4}$--is catalyzing rapid growth in efforts towards decarbonization.

Adding to this dynamism are new books addressing the multifarious causes, consequences and challenges of climate change. Climate Change: Biological and Human Aspects, by Jonathan Cowie, is an impressive endeavor that weaves together discussion of both natural and social science processes associated with climate change. The author begins with a chapter on the functioning of the climate system, discussing the fundamentals of the carbon cycle, the greenhouse effect and connections to the water cycle and other biological processes. The book then covers a historical view of past climates and contributing factors that have marked past climate changes. He addresses the question "how do we know what we know about climate change?" by carefully discussing climate proxies such as tree rings, pollen, coral and peat bogs. He addresses biological processes through the 4.6 billion years of planet Earth, including discussion of the relevant Carboniferous period when coal was deposited (330 to 250 million years ago) and the Holocene epoch (10,000 years ago to the present). It is 
through these roughly one-hundred pages of great detail that Cowie successfully situates our present anthropogenic climate change predicament.

His focus sharpens when attention is paid to biological changes and human factors connected to climate change. For example, he examines shifting migration patterns spatially in different directions: vertical (e.g. up a mountainside) or horizontal (e.g. the migration range of the Monarch butterfly) or temporal/phenological (e.g. earlier flowering of a plant species). Then drawing on work from the US Global Change Research Program and the UK Climate Impacts Programme, Cowie provides carefully detailed regional case studies on these kinds of interactions over time. The book concludes with a discussion of these interacting factors, and a view to the future of energy use, carbon emissions, human and biological change and sustainability.

Cowie draws on many disciplines--such as geology, chemistry, economics--in order to interrogate climate change causes and consequences. As a result, the book's title seems unnecessarily constraining, and perhaps even misleading. Biological and human elements are privileged, but they are not the only things Cowie examines in detail. Furthermore, while the text is excellent, more photos and figures would aid in discussions throughout, especially if the book is to be used as a course text. Nonetheless, the strength of this contribution is precisely the interdisciplinary approach taken to such a multifaceted challenge. The author commendably accounts for the dynamism and agency of biophysical as well as human elements in telling this history at the human-environment interface.

Oil, Water, and Climate: An Introduction, by Catherine Gautier, reads as advertised. After initial coverage of these complex interactions, the book is divided into three major sections where emphasis is placed on each factor in turn. Gautier also emphasizes the contributing influence of population. This additional thread--though conspicuously absent in the title--stitches together many of the discussions that follow throughout the book, although consumption deserves greater scrutiny as well.

Gautier works through basic concepts linking GHG emissions with temperature change, changes in snow and ice extent, increases in oceanic heat content, precipitation changes and sea level rise. Population, climate change and other environmental impacts are then intertwined through exploration of demographic elements, differential resource use, vulnerability, risk and capacities to adapt to changing environments. The second section examines oil, focusing specifically on the "peak oil" debate as it relates to energy sources, production, distribution and consumption. This section also addresses the specifics of transportation (and connected GHG emissions), petro-geopolitics and intertwined conflicts, and alternatives. The third and largest section covers water, whose gaseous state in the atmosphere has strong absorption capacity for long-wave radiation. This section addresses the geopolitics of water, drawing heavily on transboundary environmental challenges and the consequent governance initiatives. After bringing the discussion back to climate observations and modeling, the volume finishes with a solutions-oriented discussion of energy and water as they relate to climate change. This excellent conclusion appraises the scope of ongoing challenges at the human-environment interface. It is a sober accounting of the critical energy, climate, population, water and sustainability challenges that lay ahead. In this context, the book addresses intangible cultural aspects, such as environmental stewardship and ethics, along with considerations of intergenerational equity.

Throughout the volume, Gautier effectively builds a historically-sensitive account of contested processes, while illuminating the high-stakes and unfolding challenges around oil, water and climate. But the question remains, why limit the analysis to oil, and not address all carbon-based energy sources as they relate to climate and water? Coal and natural gas need not be ignored. Perhaps her experience in teaching at the University of California, Santa Barbara plays a role. In 1969, a Union Oil platform a few miles off the coast of Santa Barbara spilled approximately 90,000 barrels into the water and onto nearby beaches. ${ }^{5}$ This event is often cited as an impetus for subsequent US federal environmental legislation, and also one that had a lasting effect on California environmental policy in terms of ongoing resistance to offshore oil drilling.

Creating a Climate for Change: Communicating Climate Change and Facilitating Social Change, edited by Susanne Moser and Lisa Dilling, extends beyond the formal spaces of science and policy emphasized in the previous two books. The book is organized in three main sections. The first works through a number of baseline elements that shape communications on climate change. These chapters then provide a strong foundation for the content of part two on "facilitating social change." This section addresses issues of individual consumption and behavioral change, political economics, and policy at various scales, including cities, states and regions, and nations. The third section works to weave the themes together through a discussion of the intersections, contestations, and dynamism of these issues. This volume most centrally considers how everyday knowledge, emotions, experiences and interactions shape the possibility for appropriate social action to address the causes and consequences of climate change. Because it is an edited book, the normative undercurrents throughout the book inevitably vary a bit more than in the Cowie and Gautier books. Moser and Dilling comment in the concluding chapter that there is "an unresolved tension running through our chapters regarding how deep societal changes in response to climate change need be" (p. 507). Moser and Dilling nonetheless work successfully to stitch together themes across the chapter contributions: countless parenthetical cross-references to other chapters and passages, as well as a useful index, build 
useful bridges for the readers.

The volume capably pursues, appraises, interrogates and refines vital challenges on the current state of communications about climate change, and discusses future directions and possibilities. The editors shed unnecessarily alienating academic jargon in favor of crisp and clearly communicated concepts and case studies. As improved communication is ultimately their goal, they provide textured accounts of interactions between climate change communications and social change. It is refreshing to see the hollow prescriptive mantra of "we just need to communicate better" forsaken for a detailed analysis.

Together, these three books raise one broad issue worth brief rumination. A key element in the Gautier book, but also discussed in Cowie, is the discussion of how "peak oil" relates the to the broader climate challenge. Gautier argues that, "peak oil has several possible consequences on energy choices both now and in the future ... the decline of the global oil supply and the consequent increasing cost of oil products mean that a country's abilities to deal with the effects of climate change will be reduced" (p. 81). To trace the capacity to address climate change challenges causally to peak oil is both distracting and damaging. If the focus is on dealing with oil scarcity, economic opportunities and benefits from a new carbon economy--clean technology development, green job creation etc.--are undermined.

Furthermore, if we compare climate change to a health issue, peak oil is a symptom of illness rather than a root cause of the problem. It is not because we are running out of oil that we have a climate crisis. Rather we have a climate crisis because there is too much oil, and powerful carbon-based industry interests have hijacked governance priorities on climate change. Granted, oil is scarce and prices are volatile. In a new report, the International Energy Agency (IEA) warns that "the era of cheap oil is over" as prices are estimated to skyrocket in the coming decades up to around $\$ 200$ a barrel by $2030 .{ }^{6}$ The IEA explicitly states that such price increases are not due to oil and gas shortages--or reaching the moment of "peak oil." Instead, "the immediate risk to supply is not one of a lack of global resources, but rather a lack of investment where it is needed." 7

If we consider the objectives of keeping carbon out (or taking it out) of the atmosphere, the urgency to decarbonize society and focus on climate adaptation has remained low because there has been too much oil. Moreover, the limiting factor is actually the capacity of the atmosphere to absorb the associated GHG emissions at the rate at which we are pumping them in via fossil fuel consumption. While there is value in discussing peak oil as it relates to geopolitics of extraction, resource use and associated inequalities, to the extent that it gains discursive traction in relation to possibilities for climate change action, it can be a red herring. This distraction represents many lurking in this climate terrain that need be debated and discussed vigorously.

Overall, these books provide a solid foundation from which to consider the aforementioned dynamic climate science, policy, and public contexts, and thus provide excellent resources for not only the classroom, but also for members of the public. There has been dramatic growth in schools and universities offering a range of climate seminars, talks, programs, courses and degrees. Cowie's book is useful as a central science text. The Gautier and Moser and Dilling books are useful for the increasing pool of climate social scientists-in-training. Each book does well to address the clear need for critical analyses that advance our understanding of social and political processes shaping the human-environment interface, and climate science and governance. As younger scholars--what some call the "me" generation of instant gratification ${ }^{8}$--may ask "what have future generations done for me lately?," these projects help people to flip that assertion on its head to instead ask questions, "what can we do for future generations?" These remain open questions, some of which Cowie, Gautier and Moser and Dilling seek to address. These books help spur on such interrogations.

\title{
FOOTNOTES
}

\author{
1 Kinver 2008. \\ 2 Summers and Carrington 2008. \\ 3 Macalister 2008. \\ 4 Daley 2008. \\ 5 Gottlieb 1993. \\ 6 International Energy Agency 2008. \\ 7 International Energy Agency 2008.
}


8 Twenge 2006.

URL: www.occ.gov/cdd/resource.htm

LOAD-DATE: April 28, 2009

LANGUAGE: ENGLISH

\section{BIBLIOGRAPHY:}

\section{References}

Daley, B. 2008. "Obama Urged to Create Green New Deal," Boston Globe, 24 November, A15.

Gottlieb, R. 1993. Forcing the Spring: The Transformation of the American Environmental Movement. Washington, D.C.: Island Press.

International Energy Agency. 2008. World Energy Outlook. Paris: OECD.

Kinver, M. 2008. "Greens Welcome New Climate Dept," BBC News Online, 3 October. Available at http://news.bbc.co.uk/1/hi/sci/tech/7650669.stm, accessed 1 December 2008.

Macalister, T. "Renewable Energy: Obama's Cruise to the White House puts the Wind Back in Green Sails," The Guardian, 7 November, p. 33.

Summers, D., and D. Carrington. 2008. "Government Pledges to Cut Carbon Emissions $80 \%$ by 2050," The Guardian, 16 October. Available at http://www.guardian.co.uk/politics/2008/oct/16/greenpolitics-edmiliband, accessed 1 December 2008.

Twenge, J. 2006. Generation Me. New York: Simon and Shuster.

PUBLICATION-TYPE: Magazine

Copyright 2009 The Center of Strategic and International Studies and the Massachusetts Institute of Technology All Rights Reserved 